Acta Theriologica 43 (1): 67-75, 1998.

PL ISSN 0001-7051

\title{
Territorial fidelity and tenure in roe deer bucks
}

\author{
John D. C. LINNELL* and Reidar ANDERSEN
}

Linnell J. D. C. and Andersen R. 1998. Territorial fidelity and tenure in roe deer bucks. Acta Theriologica 43: 67-75.

We present data on fidelity to territory, and length of tenure (multi-year) for bucks of European roe deer Capreolus capreolus (Linnaeus, 1758) based on 26 radio-collared individuals that were followed for up to 5 years. Individual bucks showed a high degree of fidelity to summer territory, with consecutive year's activity centres being less than $200 \mathrm{~m}$ apart on average. An average $70 \%$ of one year's territory was within the borders of the previous year's territory. No buck occupied a territory which did not overlap with the previous year's territory. Activity centres of consecutive winter home ranges were on average $502 \mathrm{~m}$ apart, although this difference was not significant. Several cases of switching between non-overlapping winter ranges between years were observed. Annual survival was high $(97 \%)$ and we observed only a single case of an old buck losing dominance on his former territory after a very hard winter. All other surviving bucks regained their dominance on their territories. It is suggested that the roe deer bucks were demonstrating an "always stay" strategy in order to gain the benefits of site familiarity. This is in keeping with the concept of roe deer territoriality being a relatively "low-risk low-gain" strategy where emphasis is placed on survival and multi-year tenure of a territory.

Norwegian Institute for Nature Research, Tungasletta-2, 7005 Trondheim, Norway

Key words: Capreolus capreolus, territoriality, resource defence, dispersal, site fidelity

\section{Introduction}

In a seminal paper on the causes of opposing sex biases in dispersal in birds and mammals, Greenwood (1980) proposed that mating system was probably the most important determinant of which sex should demonstrate the greatest tendency to disperse. He argued that male birds, by virtue of their resource defence mating system, should be more philopatric than females, while male mammals, with mate defence mating strategies, should be less philopatric than females. This is true for both natal dispersal (emigration of juveniles) and breeding dispersal (movement between consecutive breeding seasons) patterns. The presence of resource defence strategies and female biased dispersal in a few mammal species for which he had data was taken as further evidence for his theory (Greenwood 1980). Greenwood was aware of the common occurrence of resource defence

*Correspondence address: Hedmark College, Evenstad, 2480 Koppang, Norway; fax: 4762463230 , e-mail: john.linnell@spe.hihm.no 
strategies among ungulates, and lamented the absence of available data at that time.

Since then there has been little change in this situation. Most studies on mating system among ungulates have traditionally concentrated on highly polygynous species that live in open habitats with mate defence, or lek, mating strategies (eg Clutton-Brock et al. 1982, 1993, Gosling 1986). By contrast territorial species are much less well understood. Even among territorial species, most research has been on the highly dimorphic species (Jarman 1979, Wirtz 1981) that have very short tenure times on territories (shorter than a breeding season); little attention has been paid to the relatively monomorphic species which hold stable territories, often in closed habitats (Hendrichs 1975, Dunbar and Dunbar 1980, Komers 1996). Those studies that do exist concentrate mainly on natal dispersal, with breeding dispersal/fidelity being almost completely disregarded.

The European roe deer Capreolus capreolus (Linnaeus, 1758) is such a species, with low sexual dimorphism, and males having a territorial mating system in summer (Bramley 1970, Johansson 1996a, b). It is not clear if roe deer territories exactly conform to a standard resource defence territory as seen in many birds, or if they represent the limits of a spatially localised dominance system (Owen-Smith 1977, Liberg et al., in press). However, they are defended throughout the summer (4 months), contain enough food and cover resources for the resident buck and several partially overlapping females, and at high density form a continuos, or slightly overlapping, mosaic (Bramley 1970, Johansson 1996b, Chapman et al. 1993, Andersen et al. 1995). Therefore, we believe that they display some components that are analogous to resource defence territories. Accordingly, from existing theory (Greenwood 1980) we would predict that roe deer bucks should, like many male birds, be faithful to territorial sites and show no breeding dispersal.

Associated with breeding site fidelity is tenure time or the number of breeding seasons for which a male can return to and defend his territory. Securing access to mates involves a number of risks such as loss of condition, injury during intra-sexual combat, and increased risk of predation (Clutton-Brock et al. 1982, Gosling et al. 1987). Species with mobile, dominance-oriented mating systems (eg harem defence) are often exposed to all of the above risks during the mating season, yet the possibilities of gaining access to many females apparently outweigh the cost. In contrast, territoriality is often regarded as being a "low-risk low-gain" reproductive strategy (Owen-Smith 1977). The success of a territorial mating system based on relatively little investment during one mating season is obviously dependent on a high probability of being able to defend a territory over several seasons (Tilson and Tilson 1986). Accordingly a long tenure time would be expected for roe deer.

To examine these predictions concerning territorial fidelity and tenure we present data based on radio-telemetry for roe deer bucks living in a high density population in an agricultural landscape in central Norway. 


\section{Study area and methods}

The study was conducted within a $8 \mathrm{~km}^{2}$ section of the $10.5 \mathrm{~km}^{2}$ island of Storfosna on the coast of central Norway $\left(63^{\circ} 40^{\prime} \mathrm{N}, 9^{\circ} 25^{\prime} \mathrm{E}\right)$. The study area was characterised by a patchwork of small woodlots $(12 \%)$, pasture $(36 \%)$, moorland $(33 \%)$, and abandoned meadows $(19 \%)$. The climate was mild and moist. Winter snowfall was generally light and snowcover discontinuous, except for the winter of 1993/94 when snow was present for over 3 months. Animals were captured either in winter in canon nets and drop nets or as fawns (Andersen et al. 1995). Although over 200 roe deer were radio-collared at various stages of the project, this study concerns 26 individual males that were radio-collared and followed for periods ranging from 2 to 5 years. Bucks were defined as fawn ( $0-12$ months), yearling (13-24 months), or adult ( $>24$ months, therefore this category also includes 2 years old animals). Although bucks were also territorial in May and June (Johansson 1996a), all matings occurred in July and August (Linnell and Andersen, in press), so we concentrated our rutting studies in this period when the benefits of territoriality are achieved. There were no predators, and legal hunting was stopped during most of the study. Accordingly, population density (as determined by visual mark-recapture methods) increased steadily from $10 \mathrm{inds} / \mathrm{km}^{2}$ in spring 1991 to $40 \mathrm{inds} / \mathrm{km}^{2}$ in autumn 1993 .

During winter (January-March) 16 to 20 radio-tracking locations were collected during either 5 or 10 ten-day-periods each month. During summer (July-August) radio-tracking locations were collected either four times a day for 15 days each month or twice a day during the entire period. Radio-tracking was staggered to take in all hours of the 24 hour cycle more or less equally. At least 6 hours separated locations. We set an arbitrary limit of a minimum of 30 locations for the calculation of home ranges. Based on experience and tests, locations were believed to have an error of less than $25 \mathrm{~m}$.

Following the critique of Maher and Lott (1995), we will make clear the definitions of territoriality that operated in this study. Conceptually we define a territory as a spatially localised dominance (Owen-Smith 1977), where a resident buck reacts aggressively to intruders. Although this involves the defence of an area it does not imply exclusive use of the total area. Operationally we defined a territorial buck as one able to establish residence within a defined and discrete area. This definition included those older bucks that were fully territorial and some 2 year olds that displayed satellite or peripheral territorial strategies (Liberg et al., in press). The movements of non-territorials (yearlings) were markedly different and were characterised by very large home ranges (Bideau et al. 1993, Andersen et al. 1995, Liberg et al., in press). Where possible this was supported with chance observations of marking and/or aggressive behaviour made during routine field work. The open agricultural landscape and the intensity of field work ensured that most animals were observed regularly.

Fidelity was measured in terms of the linear distance between seasonal home range/territory centres [here taken as the Kernel centre after Worton (1989)] and the degree of home range/territory overlap [concave polygons after Harvey and Barbour (1965)] in consecutive years. Territory turnover was measured in terms of the percentage of adult bucks which failed to return to a territory each summer, after having been territorial the previous summer. Because of the open habitat of the study site and the intensity of our routine activities most individuals were seen regularly (by chance) even when radio-collars stopped working, and it was possible to determine whether these bucks were alive and still resident on their territory. These data were only used in the turnover and tenure analysis.

\section{Results}

\section{Distances between seasonal activity centres}

Adult roe deer bucks were very faithful to their summer territories. Annual averages for the distance between activity centres from consecutive year's territories were between 332 to 110 meters apart (Table 1). This value is well 
Table 1. Fidelity of adult roe deer bucks to winter home range and summer territory as measured by the linear distance (in meters) between consecutive years' kernel activity centres. Sample sizes are given in parantheses.

\begin{tabular}{lccccc}
\hline \multirow{2}{*}{ Range } & \multicolumn{5}{c}{ Distance \pm SE } \\
\cline { 2 - 6 } & $1990-91$ & $1991-92$ & $1992-93$ & $1993-94$ & Totals \\
\hline Winter & & $424 \pm 290(8)$ & $172 \pm 23(5)$ & $707 \pm 280(11)$ & $502 \pm 162(24)$ \\
Summer & $333 \pm 109(4)$ & $111 \pm 44(10)$ & $116 \pm 48(7)$ & $223 \pm 80(14)$ & $182 \pm 39(35)$ \\
\hline
\end{tabular}

within the size of a diameter of an average territory $(620 \mathrm{~m}$ for a 30 ha territory typical of our study area; Andersen et al. 1995). The annual average distances between winter ranges were higher (171 to $707 \mathrm{~m}$, Table 1 ), although they were not significantly different from the distance between consecutive territories when all years were pooled (Mann-Whitney test: $U=325, p=0.14$ ). There was no significant variation between the degree of fidelity to either territory or winter range during the years of the study (Kruskal-Wallis ANOVA: $\chi^{2}=6.18, \mathrm{df}=3$, $p=0.1 ; \chi^{2}=0.68, \mathrm{df}=2, p=0.71$ ). The longest shifts in winter home ranges (up to $2.5 \mathrm{~km}$ ) corresponded to the hard winter of 1993/94 when many bucks had to leave open habitats and find refuge in more wooded areas. This resulted in movements exceeding several home range diameters.

\section{Overlap with previous season's territory}

The percentage area overlap between consecutive territories was also high, with an average of $70 \%$ of one year's territory area within the borders of the previous year's territory (Table 2). There was significant variation between years (one-way ANOVA: $F=3.9, \mathrm{df}=3, p=0.02$ ). Scheffes post-hoc test identified this as being due to the difference in overlap between 1990 and 1991 with the overlap from the later year pairs $(p=0.02, p=0.18, p=0.05$ for $1990-91$ vs $1991-92$, 1992-93 and 1993-94 respectively). No buck ever occupied a territory which did not overlap, at least partially, with his previous year's territory.

Table 2. Percentage area overlap $( \pm \mathrm{SE})$ between one year's territory and that from the previous year, for adult male roe deer bucks. Sample sizes are given in parentheses.

\begin{tabular}{ccccc}
\hline \multicolumn{5}{c}{ Years } \\
\hline $1990-91$ & $1991-92$ & $1992-93$ & $1993-94$ & Totals \\
\hline $45 \pm 9(4)$ & $78 \pm 5(10)$ & $69 \pm 5(7)$ & $73 \pm 5(13)$ & $70 \pm 3(34)$ \\
\hline
\end{tabular}




\section{Tenure time and territory turnover}

The adult roe deer bucks in this study had a very high survival rate, despite the very high density which the population reached (Table 3 ). Only three of the bucks, for which data is presented here, died (out of 57 radio years collected from the 26 individuals presented here; $=5 \%$ ). And of these, two died in accidents that involved human factors. Of those that survived the intervening winter only one buck failed to regain his former territory (in 1994). As determined from examination of his teeth, this buck was old during all the three years he was studied (1992-1994). He was visibly in very poor condition in the severe winter of 1993/94. In the territorial season of 1994 he occupied a large range around his former territory that was now occupied by three other bucks. In a number of chance observations he was clearly sub-dominant to them. No other bucks lost their position during the study and no bucks lost their territory during a territorial season. This low rate of turnover implied that tenure time was long, with $99 \%$ of all bucks that survived the winter becoming territorial again the next season (Table 3). For example, all five bucks that were territorial in the first year of the study (1990) were still territorial in 1994.

Table 3. Percentage of adult roe deer bucks that were able to regain their territorial positions on their former territory in consecutive years. Sample sizes are given in parentheses.

\begin{tabular}{lccccc}
\hline \multirow{2}{*}{ Clan of bulls } & \multicolumn{5}{c}{ Years } \\
\cline { 2 - 5 } & $1990-91$ & $1991-92$ & $1992-93$ & $1993-94$ & Totals \\
\hline $\begin{array}{l}\text { \% of all bucks } \\
\% \text { of survivors }\end{array}$ & $100(5)$ & $100(11)$ & $94(18)$ & $87(23)$ & $95(57)$ \\
\hline
\end{tabular}

\section{Discussion}

Most studies on roe deer have commented on the stability of roe deer buck annual home ranges (Bideau et al. 1993) and territories (Bramley 1970, Strandgaard 1972, Bjar et al. 1991, Danilkin 1996), although none of these authors have provided quantitative measures of this fidelity to territory. Adult roe deer bucks in our study showed a very high degree of fidelity to their summer territories, invariably defending the same territory in consecutive years if they survived the intervening winter. Although territorial "borders" (Walther et al. 1983) appeared to adjust slightly from year to year (overlap was not $100 \%$ ), the centre of activity remained functionally static and no buck occupied consecutive territories that did not overlap. These fluctuations in territory borders could represent minor adjustments to the increasing population density, changes in the ownership of neighbouring territories, or changes in crop distribution in this predominantly 
agricultural landscape. The average annual shift in activity centre of $180 \mathrm{~m}$ is identical to the only comparable value from a Swedish study (Johansson 1996b). This finding is in agreement with Greenwood's hypothesis that breeding dispersal should be unusual among male ungulates that hold resource based mating territories.

Because home range fidelity appears to be a common phenomena among ungulates like roe deer (Linnell and Andersen 1995, this study), moose Alces alces (Sweanor and Sandegren 1989, Andersen 1991) and white-tailed deer Odocoileus virginianus (Nixon et al. 1992) there are likely to be some somatic advantages to fidelity. Although none of the possible somatic advantages that territorial fidelity could confer were measured in this study, it is likely that the principles that apply to other animal groups also apply to roe deer. Because of the length of the territorial period of roe deer (May-August) a territory must serve as a long term food source for both the territorial buck and overlapping reproductive females (Chapman et al. 1993). Increased foraging efficiency resulting from range familiarity is therefore likely to be favoured as it would allow greater time to be spent on territorial maintenance activities (Rydell 1989) with little cost. Familiarity with an area is likely to improve predator detection and escape behaviour (Metzgar 1967, Clarke et al. 1993). Lastly, the dangerous nature of the roe deer's weapons (antlers) and the general low levels of physical contact occurring (Andersen et al. 1995) imply that it is likely that some type of "resident always wins" rule should be favoured in combat (Stamps 1987). Stability of membership within the territorial mosaic is likely to further reduce the interaction rates associated with "testing" neighbours, in the same way that familiar females show reduced aggression (Thouless 1990). In addition the territory site should help serve as a reference cue for the individual holding buck's dominance (Gosling 1986).

The high population density of this population resulted in a "super-saturated" territorial mosaic, which could have imposed a very high cost on any buck attempting to switch territory (Switzer 1993). The significant increase in overlap with the previous years territory as the study advanced could be due to the greater packing of territories with increasing population density. Although the territory mosaic broke down each winter and bucks could have tried to establish on new territories each spring at the onset of the territorial phase, none did so. It is therefore likely that both benefits of staying, and the possible costs of switching (increased aggression), produced the observed pattern of fidelity. This indicates that roe deer bucks operate under an "always-stay" rule when faced with changing conditions (Switzer 1993), at least with respect to summer territory and the changes resulting from increasing population density reported here.

In contrast to the summer situation, some bucks were not always faithful to winter ranges, in some cases switching between different (non-overlapping) winter ranges in different years. Such movements should have little social cost due to the absence of intra-sexual aggression in winter, and several benefits as it allowed access to the more variable resource distribution associated with winter. 
Associated with the observed territorial fidelity was a long tenure time. Bucks had a high probability of being territorial for many years. Clearly this could compensate for the relatively low energetic investment in mating made each year (Johansson 1996b, Liberg et al., in press). Tenure time is measured in weeks or months, rather than years, in species such as fallow deer Dama dama, gazelles Gazella sp. and impala Aepyceros melampus (Jarman 1979, Walther et al. 1983, Moore et al. 1995) which show greater sexual dimorphism. Female group size is also larger in these species, providing potentially greater immediate rewards for successful males. The stable, scattered and solitary distribution of roe deer females means that such rewards are not available to a successful roe deer buck. It is widely assumed that female distribution and behaviour determines male spacing behaviour, and in the case of roe deer this probably sets the limits on potential polygyny levels (Clutton-Brock et al. 1980). There is therefore little to be gained by excessive energy expenditure on mating within a given season (Owen-Smith 1977).

It should be born in mind that this study site lacked both predators and hunting during the study period. The presence of these factors would obviously reduce the expected tenure time of bucks through increased mortality (eg Tilson and Tilson 1986) although experimental evidence from Britain and Sweden indicates that even the presence of vacant territories does not immediately attract neighbouring bucks to shift territory (Bramley 1970, Cederlund et al. 1994).

In conclusion, the observed patterns of territorial fidelity and long (multi-year) tenure times of roe deer bucks in a very high density population are consistent with a strategy of relatively low annual investment in mating, traded against the possibility of maintaining this investment over many years. Greenwood's (1980) hypothesis of little male breeding-dispersal in a resource defending mammal is supported. The generality of this model for other "monomorphic" resource-defending forest ungulates will require further work.

Acknowledgements: These data were collected during a five year study of roe deer behavioural ecology and population dynamics funded by the Norwegian Directorate for Nature Management, the Norwegian Institute for Nature Research and the environmental protection offices of Sør-Tørndelag, Nord-Tørndelag and Nordland Counties. We are grateful to all the students and field assistants who assisted with field work, and the landowners of Storfosna for allowing us to work on their land. O. Liberg, J. Swenson, O. R. Fremming and S. A. Hoem have commented on early versions of the manuscript and provided helpful discussions. Three annoymous referees greatly improved an earlier version of the manuscript.

\section{References}

Andersen R. 1991. Habitat deterioration and the migratory behaviour of moose (Alces alces L.) in Norway. Journal of Applied Ecology 28: 102-108.

Andersen R, Linnell J. D. C. and Aanes R. 1995. [Roe deer in an agricultural landscape. Final report]. Norwgian Institute for Nature Research Fagrapport 10: 1-80. [In Norwegian with English abstract] 
Bideau E., Vincent J. P., Quere J. P. and Angibault J. M. 1983. Occupation de l'espace chez l'e chevreuil (Capreolus capreolus L., 1789). Acta Oecologica, Oecologica Applicata 4: 163-184.

Bideau E., Gerard J. F., Vincent J. P. and Maublanc M. L. 1993. Effects of age and sex on space occupation by European roe deer. Journal of Mammalogy 74: 745-751.

Bjar G., Selås V., Lund L. O. and Hjejord O. 1991. Movements and home range dynamics of roe deer, Capreolus capreolus L., in southeastern Norway. Fauna Norvegica 12A: 12-18.

Bramley P. S. 1970. Territoriality and reproductive behaviour of roe deer. Journal of Reproduction and Fertility, Supplement 11: 43-70.

Cederlund G., Kjellander P. and Liberg O. 1994. Effects of buck hunting on spatial distribution among roe deer Capreolus capreolus L. Proceedings of the International Union of Game Biologists Congress 21: 271-278.

Chapman N. G., Claydon K., Claydon M., Forde P. G. and Harris S. 1993. Sympatric populations of muntjac (Muntiacus reevesi) and roe deer (Capreolus capreolus): a comparative analysis of their ranging behaviour, social organization and activity. Journal of Zoology, London 229: 623-640.

Clarke M. F., da Silva K. D., Lair H., Pocklington R., Kramer D. L. and McLaughlin R. L. 1993. Site familiarity affects escape behaviour of the eastern chipmunk, Tamias striatus. Oikos 66: $533-537$.

Clutton-Brock T. H., Albon S. D. and Harvey P. H. 1980. Antlers, body size and breeding group size in the Cervidae. Nature 285: 565-567.

Clutton-Brock T. H., Guinness F. E. and Albon S. D. 1982. Red deer. Behaviour and ecology of two sexes. Edinburgh University Press, Edinburgh: 1-378.

Clutton-Brock T. H., Deutsch J. C. and Nefdt R. J. C. 1993. The evolution of ungulate leks. Animal Behaviour 46: 1121-1138.

Danilkin A. 1996. Behavioural ecology of Siberian and European roe deer. Chapman and Hall, London: 1-277.

Dunbar R. I. M. and Dunbar E. P. 1980. The pairbond in klipspringer. Animal Behaviour 28: 219-229.

Gosling L. M. 1986. The evolution of the mating strategy in male antelopes. [In: Ecological aspects of social evolution. D. I. Rubenstein and R. W. Wrangham, eds]. Princeton University Press, New Jersey: 244-281.

Gosling L. M., Petrie M. and Rainy M. E. 1987. Lekking in topi: a high cost, specialist strategy. Animal Behaviour 35: 616-618.

Greenwood P. J. 1980. Mating systems, philopatry and dispersal in birds and mammals. Animal Behaviour 28: 1140-1162.

Harvey M. J. and Barbour R. W. 1965. Home range of Microtus ochrogaster as determined by a modified minimum area method. Journal of Mammalogy 46: 398-402.

Hendrichs H. 1975. Changes in a population of dikdik, Madoqua (Rhynchotragus) kirki (Günther 1880). Zeitschrift für Tierpsychologie 38: 55-69.

Jarman M. V. 1979. Impala social behaviour: territiory, heirarchy, mating, and the use of space. Advances in Ethology 21: 1-92.

Johansson A. 1996a. Territory establishment and antler cycle in male roe deer. Ethology 102: 549-559.

Johansson A. 1996b. Territorial dynamics and marking behaviour in male roe deer. Ph D thesis, Stockholm University, Stockholm.

Komers P. 1996. Obligate monogamy without paternal care in Kirks dikdik. Animal Behaviour 51: 131-140.

Liberg O., Johansson A., Andersen R. and Linnell J. D. C. (in press) Mating system, mating tactics and the function of male territoriality in roe deer. [In: European roe deer: the biology of success. R. Andersen, P. Duncan and J. D. C. Linnell, eds]. Scandinavian Universit

Linnell J. D. C. and Andersen R. 1995. Site tenacity and logging disturbance in roe deer. Wildlife Society Bulletin 23: 31-36.

Linnell J. D. C and Andersen R. (in press). Timing and synchrony of birth in $a$ hider species, the roe deer Capreolus capreolus. Journal of Zoology, London. 
Maher C. R. and Lott D. F. 1995. Definitions of territoriality used in the study of variation in vertebrate spacing systems. Animal Behaviour 49: 1581-1597.

Metzgar L. H. 1967. An experimental comparison of sceech owl predation on resident and transient white-footed mice Peromyscus leucopus. Journal of Mammalogy 48: 387-391.

Moore N. P., Kelly P. F., Cahill J. P. and Hayden T. J. 1995. Mating strategies and mating success of fallow (Dama dama) bucks in a non-lekking population. Behavioural Ecology and Sociobiology 36: 91-100.

Nixon C. M., Hansen L., Brewer P. A. and Chelsvig J. E. 1992. Stability of white-tailed doe parturition ranges on a refuge in east-central Illinois. Canadian Journal of Zoology 70: 968-973.

Owen-Smith N. 1977. On territoriality in ungulates and an evolutionary model. Quarterly Review of Biology 52: 1-38.

Rydell J. 1989. Site fidelity in the northern bat (Eptesicus nilssoni) during pregnancy and lactation. Journal of Mammalogy 70: 614-617.

Stamps J. A. 1987. The effect of familiarity with a neighborhood on territory acquisition. Behavioural Ecology and Sociobiology 21: 273-277.

Strandgaard H. 1972. The roe deer (Capreolus capreolus) population at Kalø and the factors regulating its size. Danish Review of Game Biology 7: 1-205.

Sweanor P. Y. and Sandegren F. 1989. Winter-range philopatry of seasonally migratory moose. Journal of Applied Ecology 26: 25-33.

Switzer P. V. 1993. Site fidelity in predictable and unpredictable habitats. Evolutionary Ecology 7: $533-555$.

Thouless C. R. 1990. Feeding competition between grazing red deer hinds. Animal Behaviour 40: $205-211$.

Tilson R. L. and Tilson J. W. 1986. Population turnover in a monogamous antelope (Madoqua kirki) in Namibia. Journal of Mammalogy 67: 610-613.

Walther F. R., Mungall E. C. and Grau G. A. 1983. Gazelles and their relatives. Noyes Publications, Park Ridge, New Jersey.

Wirtz P. 1981. Territorial defence and territory take-over by satelite males in the waterbuck (Kobus ellipsirymnus). Behavioural Ecology and Sociobiology 8: 161-162.

Worton B. J. 1989. Kernel methods for estimating the utilization distribution in home range studies. Ecology 70: 164-168.

Received 20 December 1996, accepted 10 September 1997. 